\title{
Improved Survival after Implementation of Multidisciplinary Team Meetings, Perioperative Chemotherapy, Extended Lymphnode Dissection and Laparoscopic Surgery in the Treatment of Advanced Gastric Cancer
}

\author{
Robin Gaupset ${ }^{1,2}$, Lars Lohne Eftang1, Odd Langbach1, Katrin Fridrich ${ }^{3}$, Arne Borthne,4, \\ Jonn Terje Geitung ${ }^{2,4}$, Sutharsan Suntharalingam ${ }^{5}$, Dejan Ignjatovic ${ }^{1,2}$, Ola Røkke ${ }^{1,2}$ \\ ${ }^{1}$ Department of Digestive Surgery, Akershus University Hospital, Lørenskog, Norway \\ ${ }^{2}$ Faculty of Medicine, Universtity of Oslo, Nydalen, Oslo, Norway \\ ${ }^{3}$ Department of Pathology, Akershus University Hospital, Lørenskog, Norway \\ ${ }^{4}$ Department of Radiology, Akershus University Hospital, Lørenskog, Norway \\ ${ }^{5}$ Department of Oncology, Akershus University Hospital, Lørenskog, Norway \\ Email: ^lapsurgeon2011@hotmail.com, Lars.Lohne.Eftang@ahus.no, Odd.Langbach@ahus.no, Katrin.Fridrich@ahus.no, \\ Arne.Borthne@ahus.no, Jonn.Terje.Geitung@ahus.no, Sutharsan.Suntharalingam@ahus.no, Dejan.Ignjatovic@ahus.no, \\ Ola.Rokke@medisin.uio.no
}

How to cite this paper: Gaupset, R., Eftang, L.L., Langbach, O., Fridrich, K., Borthne, A., Geitung, J.T., Suntharalingam, S., Ignjatovic, D. and Røkke, O. (2018) Improved Survival after Implementation of Multidisciplinary Team Meetings, Perioperative Chemotherapy, Extended Lymphnode Dissection and Laparoscopic Surgery in the Treatment of Advanced Gastric Cancer. Journal of Cancer Therapy, 9, 106-117.

https://doi.org/10.4236/jct.2018.92012

Received: December 20, 2017

Accepted: January 30, 2018

Published: February 2, 2018

\begin{abstract}
Aims: The treatment of gastric cancer has changed in the western countries during the last decade. This includes multidisciplinary team (MDT) meetings, perioperative chemotherapy, extended lymph node dissection, and laparoscopic surgery, all of which were gradually implemented at our department from 2008. The aim of the present study was to determine the effect of these changes on morbidity and survival. Material and Methods: 185 patients with gastric cancer were operated with curative intent from 2000 until 2016 in this retrospective, observational, follow-up study; 83 before implementation of modern principles in 2008 (period 1) and 102 were treated after 2008 (period 2). Results: The resection rate ( $94 \%$ vs $92.8 \%$ ) and mortality rates $(4.8 \%$ vs $2.9 \%$ ) did not differ between the two periods. In period 2, 48 patients (47.1\%), received neoadjuvant chemotherapy. In 36 patients (35.3\%), laparoscopic surgery with D2 lymphadenectomy was performed. There was a significantly higher yield in the number of lymph nodes in period 2 compared to period 1 (14 vs $8, p<0.001)$. This is also apparent between laparoscopic and open
\end{abstract}


Copyright () 2018 by authors and Scientific Research Publishing Inc. This work is licensed under the Creative Commons Attribution International License (CC BY 4.0).

http://creativecommons.org/licenses/by/4.0/

Open Access surgery in the second period ( 32 vs $10, \mathrm{p}<0.001$ ). The five-year survival rate was significantly improved after the change in treatment principles with an estimated improvement from $30 \%$ to $40 \%$ between the periods ( $p=0.033$ ). Conclusion: The combined effect of MDT meetings, neoadjuvant chemotherapy, extended lymphnode dissection and laparoscopy has improved the prognosis of gastric cancer patients.

\section{Keywords}

Gastric Cancer, Chemotherapy, Laparoscopy, Survival, D2 Lymphadenectomy

\section{Introduction}

Gastric cancer ranks as the second leading cause of cancer-related death in the world and is the fourth most common cancer worldwide [1]. In Norway (population 5.3 million), as in most western countries, there has been a steady decline in the incidence of this cancer in the last four to five decades, with less than 500 new cases annually. Even though the survival rate has improved in the same period from $12.5 \%$ in the period $1971-1975$ to $23.9 \%$ in the period 2006-2010, the survival rates of gastric cancer are still low compared to other forms of cancer [2]. During the last decade, several improvements have been incorporated in the treatment. Neoadjuvant chemotherapy has been shown to improve survival [3]. Standardization of surgery, especially with emphasis on extended lymphadenectomy at the D2 level according to the Japanese and Korean guidelines [4] [5], also improved survival rates [6]. The implementation of multidisciplinary team (MDT) discussions to improve preoperative staging and optimize treatment selection [7] [8], reduction in number of surgical units to increase volume per surgeon and center and the use of laparoscopic surgery are also considered important quality-enhancing factors [9]. Neoadjuvant chemotherapy and MDTmeetings were introduced in Norway in 2006 [10], and implemented at our institution in 2008. The surgical technique was standardized and the number of surgeons involved was reduced. A strict adherence to D2 lymphadenectomy, performed laparoscopically by selected surgeons, has been our standard from January 2013. The purpose of this study was to evaluate the effects of these combined measures with regards to morbidity and survival of gastric cancer patients. A comparable study was conducted by Bringeland et al., but did not show any difference before and after introduction of perioperative chemotherapy [11].

\section{Materials and Methods}

273 consecutive patients with gastric cancer were admitted to Akershus University Hospital, Norway, from January 2000 until July 2016, 127 before January 1, 2008 (period 1) and 146 after January 1, 2008 (period 2). Distant metastases were diagnosed in 61 patients and surgery was not performed. Seven patients were 
diagnosed with locally advanced disease and were treated with palliative procedures. In six patients, gastric cancer was diagnosed during emergency surgery due to other suspected diseases and/or perforation. Ten patients had severe comorbidity and four patients refused surgery, leaving 185 patients for potential curative treatment, 83 before 2008, and 102 after 2008 (Figure 1). These patients were included in this retrospective, observational, follow-up study with an intention-to-treat design. The sample size was calculated based on an assumption of a $20 \%$ increase in five-year survival (from $20 \%$ to $40 \%$ ) after the changes in treatment at our department. With a test strength of 80 , and level of significance of 0.05 , the calculated number of patients needed in each group was 79 patients. The variables that needed to be analyzed were the use of perioperative chemotherapy, the surgical technique (open vs laparoscopy), the level of lymphadenectomy (D1 vs D2) as well as operative characteristics to compare the groups.

From 2008 onwards, the department made several changes in the treatment principles; the use of neoadjuvant chemotherapy, MDT meetings, laparoscopic surgery and D2 lymphadenectomy, creating a logical distinction of the material into two groups.

Every patient was subjected to a preoperative work-up as soon as the cancer was diagnosed by endoscopy with a highly suspicious lesion and/or positive findings on biopsy.

Clinical work-up

A thorough examination with laboratory work-up and evaluation of relevant comorbidities were performed. Patients in need of optimization were referred to relevant specialists.

\section{Radiology}

All patients were subjected to radiological staging with thoracoabdominal CTimaging to evaluate the local, regional and distant aspects of their disease. At the end of period 2, a specific $\mathrm{CT}$ of the distended stomach by $\mathrm{CO}_{2}$ tablets was implemented in the protocol for evaluation of the tumor.

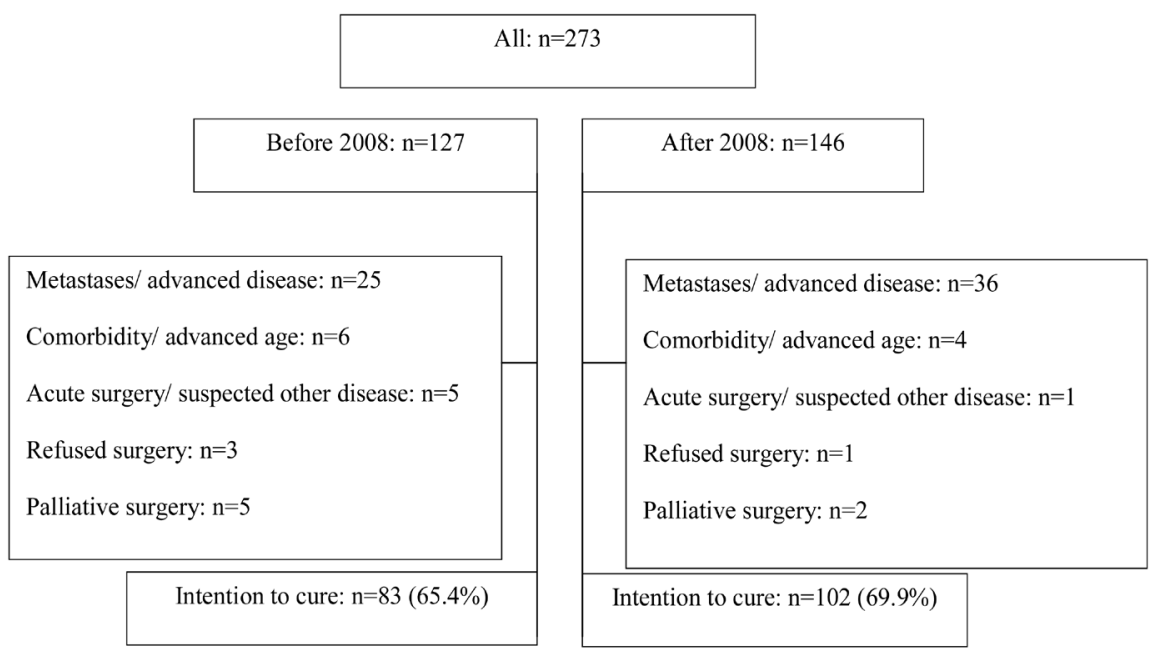

Figure 1. Consort diagram of patients admitted with gastric cancer 2000-2016. 
$\underline{\text { MDT }}$

Multidisciplinary team meetings were implemented in 2008. Each case was discussed with regards to tumor characteristics, operability, fitness for neoadjuvant chemotherapy and surgery.

Oncological treatment

In patients judged fit and potentially curable, a course of three cycles constituting Epirubicin $50 \mathrm{mg} / \mathrm{m}^{2} \times 1$ intravenously (iv) every three weeks, Oxaliplatin $130 \mathrm{mg} / \mathrm{m}^{2} \times 1$ iv every three weeks and Xeloda (Capecitabine) $625 \mathrm{mg} / \mathrm{m}^{2} \times 2$ per orally (po) (EOX-regime) for nine weeks were administered preoperatively. Four to six weeks after completion of this course, the patients were admitted for surgery. The treatment course was then repeated four to six weeks after surgery. Surgical technique

From 2000 until 2013 the standard approach was open surgery with a D1 resection, at best removing lymph node stations 1, 3, 4d and 4sb (4sa and 2 were removed in gastrectomies). The procedure was performed by a relatively large number of surgeons in the department, although experienced senior surgeons always attended as operator or assistant. From 2013 a change in the surgical approach was implemented, with a strict adherence to D2 lymphadenectomy, according to the Japanese and Korean guidelines. In these cases, lymph node stations $1,3,4 \mathrm{~d}, 4 \mathrm{sb}, 5,6,7,8 \mathrm{a}, 9,11 \mathrm{p}$ and 12a (including 2, 4sa and 11d in gastrectomies) were removed. Furthermore, laparoscopy was established as our standard approach, emphasizing a reduction in the number of surgeons being involved and hereby raising the level of excellence.

This study was approved by The Norwegian National Committee for Medical and Health Research Ethics (case number 2017/722). All patient data were coded and blinded before analysis.

\section{Statistics}

The patient demographics, clinical characteristics and results in tables and text are presented as median and range (minimum-maximum) or as frequencies and percentages when appropriate. Categorical data were analyzed by the Pearson Chi-square test $\left(\chi^{2}\right)$. Continuous variables were compared by the Student's t test. Survival curves were calculated by Kaplan-Meyer plots, and the difference between groups was tested by the log rank test. The level of significance was set to $\mathrm{p}<0.050$. IBM ${ }^{\circledast}$ SPSS $^{\circledast}$ statistics 24 (SPSS Inc., Chicago, IL, United States) was used for statistical analysis.

\section{Results}

121 men $(65.4 \%)$ and 64 women (34.6\%) with a median age of 70.2 years (36- 89 years) were operated for gastric cancer with intention to cure in the period 2000-2016. 83 patients were treated from 2000-2008 (period 1) and 102 patients were treated from 2008-2016 (period 2). 78 (42.2\%) patients had cardiovascular issues, $10(5.4 \%)$ had pulmonary issues, leaving $26(14.1 \%)$ with other comor- 
bidities, including kidney disease, diabetes, leukemia, lymphoma and rheumatism among others. 62 (33.5\%) patients had no previous disease. There was a significant difference between the two periods with a slightly higher incidence of cardiovascular and pulmonary disease in period 2, and a higher incidence of other disease types in period 1 (Table 1 ). However, the ASA scores did not differ between the groups. Eighteen (9.7\%) and three (1.6\%) patients had previous BII or BI resection, respectively. One patient $(0.5 \%)$ had former PGV or gastroenterostomy (Table 1).

The type of resection, surgical technique and radicality are shown in Table 2. In $104(56.2 \%)$ patients a distal resection, typically a subtotal gastrectomy was performed. $68(36.8 \%)$ had a total gastrectomy, nine $(4.9 \%)$ a palliative gastroenterostomy and four (2.2\%) were explored with no further procedure performed. Of the patients where surgery was performed, 136 (73.5\%) underwent D1 lymphadenectomy and 36 (19.5\%) D2 lymphadenectomy. Open surgery was performed in $148(80.0 \%)$ patients and laparoscopic surgery were performed in 37 (20.0\%) patients. D2 lymphadenectomy and laparoscopy was only performed in the second period. R0-resection was accomplished in 151 (81.6\%) of the patients, R1 in $18(9.7 \%)$ and R2 in $3(1.6 \%), 13(7 \%)$ patients were not resected (Table 2).

Table 1. Patient characteristics.

\begin{tabular}{|c|c|c|c|}
\hline & $\begin{array}{c}2000-2008 \\
(\mathrm{n}=83)\end{array}$ & $\begin{array}{c}2008-2016 \\
(\mathrm{n}=102)\end{array}$ & $\mathrm{p}$ \\
\hline Age (median (range)) & $70.9(36-89)$ & $69.6(41-89)$ & 0.750 \\
\hline \multicolumn{4}{|l|}{$\operatorname{Sex}(n(\%))$} \\
\hline Male & $55(66.3)$ & $66(64.7)$ & \multirow{2}{*}{0.825} \\
\hline Female & $28(33.7)$ & $36(35.3)$ & \\
\hline \multicolumn{4}{|l|}{ Comorbidity $(\mathrm{n}(\%))^{\mathrm{a}}$} \\
\hline None & $25(32.5)$ & $37(37.4)$ & \multirow{4}{*}{0.033} \\
\hline Cardiovascular & $34(44.2)$ & $44(44.4)$ & \\
\hline Pulmonary & $2(2.6)$ & $8(8.1)$ & \\
\hline Other & $16(20.7)$ & $10(10.1)$ & \\
\hline \multicolumn{4}{|l|}{ ASA-score $(\mathrm{n}(\%))^{\mathrm{b}}$} \\
\hline I & $3(8.3)$ & $4(6.5)$ & \multirow{4}{*}{0.369} \\
\hline II & $18(50.0)$ & $30(48.3)$ & \\
\hline III & $15(41.7)$ & $23(37.1)$ & \\
\hline IV & 0 & $5(8.1)$ & \\
\hline \multicolumn{4}{|c|}{ Prior surgery for gastric ulcer $(\mathrm{n}(\%))^{\mathrm{c}}$} \\
\hline None & $69(85.2)$ & $91(89.2)$ & \multirow{5}{*}{0.159} \\
\hline BII & $11(13.6)$ & $7(6.9)$ & \\
\hline BI & 0 & $3(2.9)$ & \\
\hline PGV & $1(1.2)$ & 0 & \\
\hline Gastroenterostomy & 0 & $1(1.0)$ & \\
\hline
\end{tabular}

${ }^{\mathrm{a}} 9$ missing values, ${ }^{\mathrm{b}} 87$ missing values, ${ }^{\mathrm{C}} 2$ missing values. 
Table 2. Type of resection, surgical technique and radicality.

\begin{tabular}{|c|c|c|c|}
\hline & $\begin{array}{c}2000-2008 \\
(\mathrm{n}=83)\end{array}$ & $\begin{array}{c}2008-2016 \\
(\mathrm{n}=102)\end{array}$ & $\mathrm{p}$ \\
\hline \multicolumn{4}{|c|}{ Type of gastric resection (n (\%)) } \\
\hline Resection & $46(55.4)$ & $58(56.9)$ & \multirow{4}{*}{0.879} \\
\hline Gastrectomy & $32(38.6)$ & $36(35.3)$ & \\
\hline Gastroenterostomy & $3(3.6)$ & $6(5.8)$ & \\
\hline Exploratory lap & $2(2.4)$ & $2(2.0)$ & \\
\hline \multicolumn{4}{|c|}{ Type of lymph node dissection (n (\%)) } \\
\hline D1 & $78(94.0)$ & $58(56.9)$ & \multirow{3}{*}{$<0.001$} \\
\hline D2 & 0 & $36(35.3)$ & \\
\hline Not resected & $5(6.0)$ & $8(7.8)$ & \\
\hline \multicolumn{4}{|c|}{ Type of surgical technique (n (\%)) } \\
\hline Open surgery & $83(100.0)$ & $65(63.7)$ & \multirow{2}{*}{$<0.001$} \\
\hline Laparoscopic surgery & 0 & $37(36.3)$ & \\
\hline \multicolumn{4}{|l|}{ Radicality (n (\%)) } \\
\hline R0 & $69(83.1)$ & $82(80.4)$ & \multirow{4}{*}{0.936} \\
\hline $\mathrm{R} 1$ & $8(9.7)$ & $10(9.8)$ & \\
\hline R2 & $1(1.2)$ & $2(2.0)$ & \\
\hline Not resected & $5(6.0)$ & $8(7.8)$ & \\
\hline
\end{tabular}

The operative characteristics are shown in Table 3 . This table shows a significant increase in operation time (178 vs 256 minutes) from period 1 to period 2. A decrease in bleeding (500 vs $300 \mathrm{ml}$ ) and the need for peroperative blood transfusion (0 vs $0 \mathrm{ml}$ ) and intravenous fluid transfusion (5400 vs $3953 \mathrm{ml})$, and higher core temperature $\left(35.8^{\circ} \mathrm{C}\right.$ vs $\left.36.5^{\circ} \mathrm{C}\right)$ at the end of surgery are all significant differences.

The tumor growth pattern was macroscopically characterized as ulcerative in $113(61.1 \%)$ patients, polypoid in $19(10.3 \%)$ and diffuse in $24(13 \%)$ patients. Six (3.2\%) patients had no residual tumor on microscopical investigation. Stage I was determined in $50(27.0 \%)$ patients, $30(16.2 \%)$ had stage II, $58(31.4 \%)$ had stage III and $31(16.8 \%)$ had stage IV disease. There was no significant difference between the two periods for these parameters (Table 3). The number of lymph nodes removed was recorded in 172 patients with a median number of 11 (0 $65)$ lymph nodes removed. There was a highly significant difference between period 1 and 2, with a median number of eight $(0-27)$ in the first period and $14(0$ $65)$ in the second period $(\mathrm{p}<0.001)$. A sub analysis of the patients in the second period having surgery with or without D2 lymphadenectomy, also showed a highly significant difference with a median number of $10(0-36)$ in the D1 group and $32(7-65)$ in the D2 group $(\mathrm{p}<0.001)$. The number of lymph nodes with metastases was also recorded in 172 patients, and 89 (51.7\%) of these had metastases, with no significant difference between the two periods (Table 4). 
Table 3. Operative characteristics.

\begin{tabular}{cccc}
\hline & $\begin{array}{c}2000-2007 \\
(\mathrm{n}=83)\end{array}$ & $\begin{array}{c}2008-2016 \\
(\mathrm{n}=102)\end{array}$ & $\mathrm{p}$ \\
\hline $\begin{array}{c}\text { Operation time (minutes) } \\
(\text { median (range) })\end{array}$ & $178(35-467)^{\mathrm{a}}$ & $256(71-539)^{\mathrm{b}}$ & $<0.001$ \\
$\begin{array}{c}\text { Bleeding (ml) (median (range) } \\
\text { Peroperative blood transfusions } \\
(\text { no units) (median (range) })\end{array}$ & $500(0-5000)^{\mathrm{c}}$ & $300(0-3000)^{\mathrm{d}}$ & $<0.001$ \\
$\begin{array}{c}\text { Peroperative fluid infusion (ml) } \\
(\text { median (range) })\end{array}$ & $0(0-11)^{\mathrm{d}}$ & $0(0-5)^{\mathrm{e}}$ & $<0.001$ \\
$\begin{array}{c}\text { Temperature end surgery } \\
\left({ }^{\circ} \mathrm{C}\right)(\text { median (range) })\end{array}$ & $35.8(33.7-37.3)$ & $36.5(33.7-38.3)^{\mathrm{h}}$ & $<0.001$ \\
\hline
\end{tabular}

${ }^{\mathrm{a}} 11$ missing values, ${ }^{\mathrm{b}} 18$ missing values, ${ }^{\mathrm{c}} 14$ missing values, ${ }^{\mathrm{d}} 23$ missing values, ${ }^{\mathrm{e}} 15$ missing values, ${ }^{\mathrm{f}} 17$ missing values, ${ }^{\mathrm{g}} 19$ missing values, ${ }^{\mathrm{h}} 21$ missing values.

Table 4. Tumor characteristics.

\begin{tabular}{cccc}
\hline & $\begin{array}{c}2000-2007 \\
(\mathrm{n}=83)\end{array}$ & $\begin{array}{c}2008-2016 \\
(\mathrm{n}=102)\end{array}$ & $\mathrm{p}$ \\
\hline $\begin{array}{c}\text { Stage (n (\%)) } \\
\text { No residual tumor }\end{array}$ & $1(1.2)$ & $5(4.9)$ & \\
Stage 0 & 0 & 0 & \\
Stage I & $18(21.7)$ & $32(31.4)$ & 0.306 \\
Stage II & $19(22.9)$ & $21(20.6)$ & \\
Stage III & $29(34.9)$ & $29(28.4)$ & \\
Stage IV & $16(19.3)$ & $15(14.7)$ & \\
Total number & & & $<0.001$ \\
Before D2 (2008-2012) & $8(0-27)$ & $14(0-65)$ & $<0.001$ \\
After D2 (2013->) & $1.5(0-24)$ & $32(7-65)$ & 0.598 \\
With metastases & & $0(0-29)$ & $<0.001$ \\
\hline Percentage with metastases & $0.25(0-100)$ & $0(0-100)$ & \\
\hline
\end{tabular}

Postoperative complications occurred in $63(34.1 \%)$ patients as shown in Table 5.31 (16.8\%) of these had minor complications and 32 (17.3\%) had major complications according to the Clavien-Dindo classification. There was no significant difference between the two periods of interest. Reoperations were performed in 33 (17.8\%) of the patients. 17 (9.2\%) patients had single anastomotic complications with 13 (7.0\%) having leaks and four (2.2\%) having obstruction demanding surgical correction. Three (1.6\%) of the patients had blowout of the duodenal stump, three (1.6\%) were reoperated for bowel obstruction and three (1.6\%) underwent an explorative laparotomy on suspicion of a complication without significant findings. Three (1.6\%) needed reoperation for wound dehiscence. Four (2.2\%) were operated for other reasons (drainage of abscess, bleeding and cholecystectomy). No difference was shown between the periods of interest. The perioperative mortality rate was $3.8 \%$. 
Table 5. Postoperative complications.

\begin{tabular}{cccc}
\hline & $\begin{array}{c}2000-2007 \\
(\mathrm{n}=83)\end{array}$ & $\begin{array}{c}2008-2016 \\
(\mathrm{n}=102)\end{array}$ & $\mathrm{p}$ \\
\hline Complications (n (\%)) & & & \\
No complications & $49(59.0)$ & $66(64.7)$ & 0.543 \\
Minor (Clavien-Dindo $<3 \mathrm{~b})$ & $17(20.5)$ & $14(13.7)$ & $19(18.7)$ \\
Major (Clavien-Dindo 3b and 4) & $13(15.7)$ & $3(2.9)$ & \\
Mortality & $4(4.8)$ & & \\
Reoperations (n (\%)) & & $83(81.3)$ & \\
No reoperations & $69(83.2)$ & $2(7.7)$ & \\
Anastomotic leak & $5(6.0)$ & $2(2.0)$ & \\
Anastomotic obstruction & $2(2.4)$ & $2(2.0)$ & \\
Bowel obstruction & $1(1.2)$ & $2(2.0)$ & \\
Explorative laparotomy & $1(1.2)$ & $2(2.0)$ & \\
Wound dehiscense & $1(1.2)$ & $1(1.0)$ & \\
Duodenal stump blowout & $1(1.2)$ & $3(3.6)$ & \\
Others & &
\end{tabular}

Of the 102 patients in the second period, $48(47.1 \%)$ received chemotherapy preoperatively. 37 (36.3\%) received three full doses, seven (6.9\%) had a dose reduction but finished three courses while four (3.9\%) had a reduction in the number of courses. Postoperatively 38 (37.3\%) received chemotherapy, 19 (18.6\%) had three full courses, seven (6.9\%) had reduction of doses while 12 (11.8\%) had to abort before finishing three courses. Predominantly capecitabine doses were reduced touphold the chemotherapy intensity in the pre- and postoperative setting.

Figure 2 shows the five-year survival curves that demonstrate a significant increased survival rate in period 2 compared to period $1(\mathrm{p}=0.033)$.

\section{Discussion}

In this study, we have shown a significant improvement in survival rate after implementation of several presumed quality-enhancing measures. There were no significant differences between the groups related to patient and demographic characteristics, tumor characteristics, stage of disease or postoperative complications. However, there were significant differences in operative characteristics between the two periods. An increase in operating time, reduction of bleeding, need for blood and peroperative fluid transfusion and a higher core temperature at the end of surgery are all parameters which may have been affected by the introduction of laparoscopy in the second period. A sub-analysis of these parameters has not been performed, as each of the numbers in this group would be insufficient for reliable results. Only 37 of the 102 patients in this group were operated by laparoscopy. Neoadjuvant chemotherapy was introduced as a result of the findings in the MAGIC trial in 2006 [3] and was incorporated into the national guidelines for treatment of gastric cancer in Norway the same year [10]. 


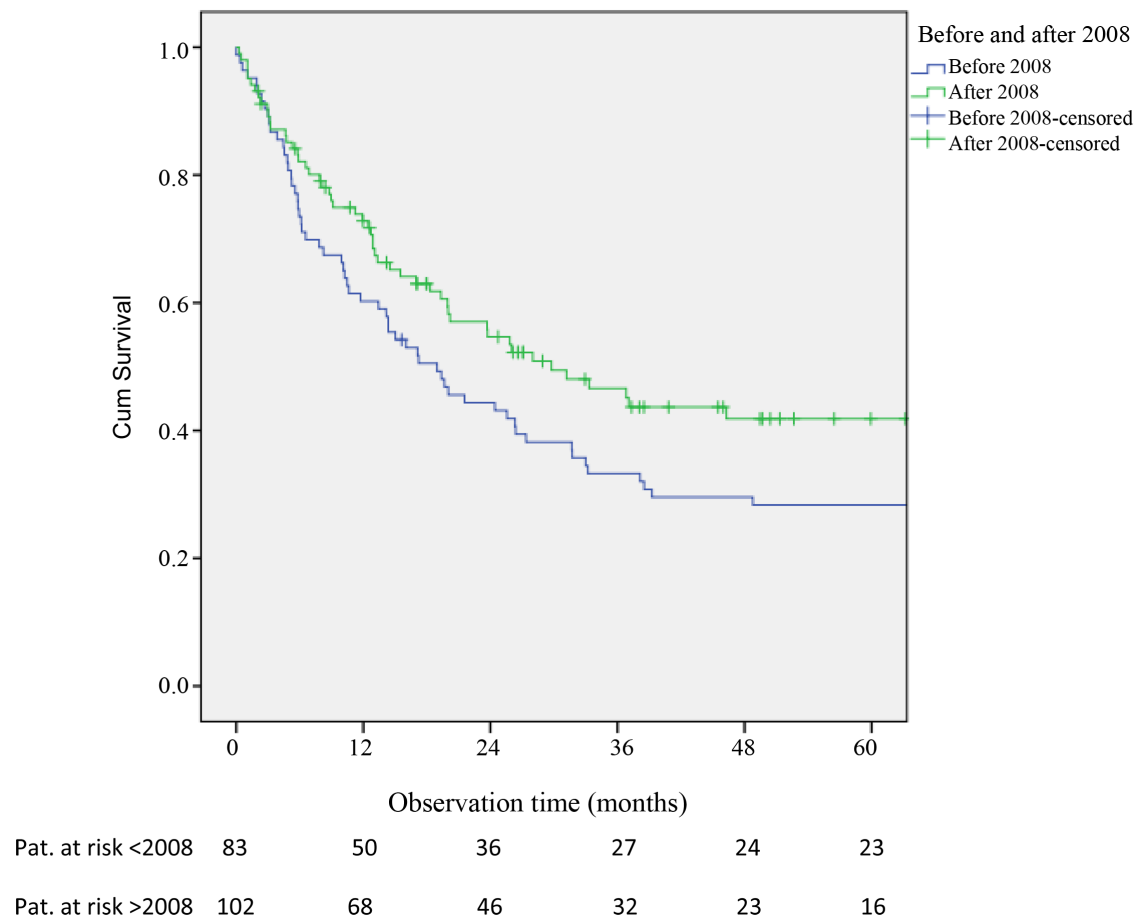

Figure 2. Comparison of long-term survival between patients treated for gastric cancer before and after 2008 by Kaplan-Meyer plot showing a significant increase in survival in the latter period $(\mathrm{p}=0.033)$.

Several trials and ongoing studies show promising results regarding survival when introducing perioperative chemo- or radio chemotherapy regimens [12]. However, other studies have failed to reproduce the findings of the MAGIC trial [13] [14] [15]. Bringeland et al. were unable to demonstrate any additional benefit of chemotherapy compared to resection and modified D2 lymphadenectomy alone. This study had a similar design to the current study. However, the surgical technique and the use of MDT-meetings did not differ between the groups compared. The study concluded that no survival benefit of chemotherapy was demonstrated. The authors suggested the effect of chemotherapy might be beneficial when substandard surgery is performed, and have challenged the design and conclusion of the MAGIC study [11]. Several studies have demonstrated survival benefit in D2 lymphadenectomy compared to D1 lymphadenectomy [16]-[21], which, despite increased morbidity, does not lead to significantly increased mortality [22]. This view has been advocated in Japanese and Korean publications for many years [3]. In western countries, the traditional conception has been that $\mathrm{D} 2$ dissection adds minimal benefit to survival, and increases morbidity [23]. However, in recent years, the results from the Dutch Gastric Cancer Trial have made a change in the opinion suggesting that D2 lymphadenectomy should now be the method of choice also in western countries [6] [24]. The use of laparoscopy in gastric cancer surgery has been under investigation. There is growing evidence that laparoscopy is non-inferior to open surgery in the treatment of both early and advanced gastric cancer with regards to oncological out- 
come [4] [25]. With regards to short term outcomes like postoperative hospital stay, blood loss and overall complication rate laparoscopic surgery is superior to open surgery [26]. Studies of the impact of MDT-meetings suggest that an improvement in preoperative staging, a higher inclusion rate of patients in ongoing trials and optimization of treatment is achieved [7] [8]. Finally, a recent report by Coburn et al. presents clinical practice guidelines, and sums up current recommendations based on available literature [9]. The seven recommendations (MDT meetings and thoracoabdominal CT scans, D2 lymphadenectomy, at least 16 lymph nodes, R0 margin should be achieved, nonsurgical management when metastatic disease, low mortality rate should be achieved and quality metrics for lymph nodes, margin distances, perioperative mortality and oncologic outcomes should be met) presented in this paper are in harmony with the standardized practice in our institution. The survival rate increases between the two periods and is comparable to that observed in many western institutions [3] [6] [11]. Our study is limited by two major factors: the sample size and the gradual, rather than abrupt, implementation of the changes. This reduces the power of a meaningful multi-variable regression analysis, which has therefore not been performed. For this reason, we are unable to reliably identify the individual contribution of each the implemented factors. Nevertheless, we strongly believe that it is the combined effect of MDT meetings, neoadjuvant chemotherapy, extended lymph node dissection and meticulous laparoscopic technique which has resulted in the significant increase in survival.

There is a need for further improvement in survival and morbidity for the gastric cancer patients, as this disease still carries a very poor prognosis. We believe improvement of gastric cancer care could be achieved through structured, preoperative conditioning and postoperative rehabilitation, better chemotherapeutic agents with less side-effects, increased proficiency in advanced laparoscopic surgery and tailored treatment based on individual variations in cancer biology. At our department, we will continue to implement necessary changes in the future.

\section{Conclusion}

The combined effect of implementation of MDT meetings, perioperative chemotherapy, extended lymph node dissection and laparoscopic technique has improved the prognosis of gastric cancer patients without increasing morbidity.

\section{Conflict of Interest}

The authors report no conflict of interest.

\section{References}

[1] Karimi, P., Islami, F., Anandasabapathy, S., Freedman, N.D. and Kamangar, F. (2014) Gastric Cancer: Descriptive Epidemiology, Risk Factors, Screening, and Prevention. Cancer Epidemiology, Biomarkers and Prevention, 23, 700-713. https://doi.org/10.1158/1055-9965.EPI-13-1057 
[2] Cancer Registry of Norway (2017) Cancer in Norway 2016-Cancer Incidence, Mortality, Survival and Prevalence in Norway. Cancer Registry of Norway, Oslo.

[3] Cunningham, D., Allum, W.H., Stenning, S.P., Thompson, J.N., Van der Velde, C.J.H., Nicolson, M., Scarffe, J.H., Lofts, F.J., Falk, S.J., Iveson, T.J., Smith, D.B., Langley, R.E., Verma, M., Weeden, S. and Chua, Y.J. (2006) Perioperative Chemotherapy versus Surgery Alone for Resectable Gastroesophageal Cancer. New England Journal of Medicine, 355, 11-20. https://doi.org/10.1056/NEJMoa055531

[4] Cui, M., Xing, J.D., Yang, W., Ma, Y.Y., Yao, Z.D., Zhang, N. and Su, X.Q. (2012) D2 Dissection in Laparoscopic and Open Gastrectomy for Gastric Cancer. World Journal of Gastroenterology, 18, 833-839.

http://www.wjgnet.com/1007-9327/full/v18/i8/833.htm https://doi.org/10.3748/wjg.v18.i8.833

[5] Tamura, S., Takeno, A. and Miki, H. (2011) Lymph Node Dissection in Curative Gastrectomy for Advanced Gastric Cancer. International Journal of Surgical Oncology, 2011, Article ID: 748745. https://doi.org/10.1155/2011/748745

[6] Songun, I., Putter, H., Kranenbarg, E.M.-K., Sasako, M. and van de Velde, C.J.H. (2010) Surgical Treatment of Gastric Cancer: 15-Year Follow-Up Results of the Randomised Nationwide Dutch D1D2 Trial. Lancet Oncology, 11, 439-449. https://doi.org/10.1016/S1470-2045(10)70070-X

[7] Davies, A.R., Deans, D.A., Penman, I., Plevris, J.N., Fletcher, J., Wall, L., Phillips, H., Gilmour, H., Patel, D., de Beaux, A. and Paterson-Brown, S. (2006) The Multidisciplinary Team Meeting Improves Staging Accuracy and Treatment Selection for Gastro-Esophageal Cancer. Diseases of The Esophagus, 19, 496-503.

[8] Lim, H.K., Stiven, P.N. and Aly, A. (2016) Reinterpretation of Radiological Findings in Oesophago-Gastric Multidisciplinary Meetings. ANZ Journal of Surgery, 86, 377-380. https://doi.org/10.1111/ans.12537

[9] Coburn, N., Cosby, R., Klein, L., Malthaner, R., Marmazza, J., Mercer, C.D. and Ringash, J. (2017) Staging and Surgical Approaches in Gastric Cancer: A Clinical Practice Guideline. Current Oncology, 24, 324-331. https://doi.org/10.3747/co.24.3736

[10] Hølmebakk, T., Frykholm, G. and Viste, A. (2010) A on Behalf of the Norwegian Gastrointestinal Cancer Group (NGICG). Introducing National Guidelines on Perioperative Chemotherapy for Gastric Cancer in Norway: A Retrospective Audit. European Journal of Surgical Oncology, 36, 610-616.

https://doi.org/10.1016/j.ejso.2010.05.006

[11] Bringeland, E.A., Wasmuth, H.H., Fougner, R., Mjønes, P. and Grønbech, J.E. (2014) Impact of Perioperative Chemotherapy on Oncological Outcomes after Gastric Cancer Surgery. British Journal of Surgery, 101, 1712-1722. https://doi.org/10.1002/bjs.9650

[12] Choi, A.H., Kim, J. and Chao, J. (2015) Perioperative Chemotherapy for Resectable Gastric Cancer: Magic and Beyond. World Journal of Gastroenterology, 21, 7343-7348. http://www.wjgnet.com/1007-9327/full/v21/i24/7343.htm

[13] Gabriel, E., Attwood, K., Narayanan, S., Brady, M., Nurkin, S., Hochwald, S. and Kukar, M. (2017) Does Neoadjuvant/Perioperative Chemotherapy Improve Overall Survival for T2N0 Gastric Adenocarsinoma? Journal of Surgical Oncology.

[14] Xu, A.M., Huang, L., Liu, W., Gao, S., Han, W.X. and Wei, Z.J. (2014) Neoadjuvant Chemotherapy Followed by Surgery versus Surgery Alone for Gastric Carcinoma: Systematic Review and Meta-Analysis of Randomized Controlled Trials. PLoS ONE, 9, e86941. 
[15] Wu, A.W., Xu, G.W., Wang, H.Y., Ji, J.F. and Tang, J.L. (2007) Neoadjuvant Chemotherapy versus None for Resectable Gastric Cancer. The Cochrane Database of Systematic Reviews, No. 2, CD005047.

[16] Degiuli, M., De Manzoni, G., Di Leo, A., D’Ugo, D., Galasso, E., Marelli, D., Petrioli, R., Polom, K., Roviello, F., Santullo, F. and Morino, M. (2016) Gastric Cancer: Current Status of Lymph Node Dissection. World Journal of Gastroenterology, 22, 2875-2893. https://doi.org/10.3748/wjg.v22.i10.2875

[17] Edwards, P., Blackshaw, G.R.J.C., Lewis, W.G., Barry, J.D., Allison, M.C. and Jones, D.R.B. (2004) Prospective Comparison of D1 vs. Modified D2 Gastrectomy for Carcinoma. British Journal of Cancer, 90, 1888-1892. https://doi.org/10.1038/sj.bjc.6601790

[18] Jiang, L., Yang, K.-H., Chen, Y., Guan, Q.-L., Zhao, P., Tian, J.-H. and Wang, Q. (2014) Systematic Review and Meta-Analysis of the Effectiveness and Safety of Extended Lymphadenectomy in Patients with Resectable Gastric Cancer. BJS, 101, 595-604. https://doi.org/10.1002/bjs.9497

[19] Schwarz, R.E. and Smith, D.D. (2007) Clinical Impact of Lymphadenectomy Extent in Resectable Gastric Cancer of Advanced Stage. Annals of Surgical Oncology, 14, 317-328. https://doi.org/10.1245/s10434-006-9218-2

[20] Wu, C.W., Hsiung, C.A., Lo, S.S., Hsieh, M.C., Shia, L.T. and Whang-Peng, J. (2004) Randomized Clinical Trial of Morbidity after D1 and D3 Surgery for Gastric Cancer. British Journal of Surgery, 91, 283-287. https://doi.org/10.1002/bjs.4433

[21] Biffi, R., Botteri, E., Cenciarelli, S., Luca, F., Pozzi, S., Valvo, M., Sonzogni, A., Chiappa, A., Leal Ghezzi, T., Rotmensz, N., Bagnardi, V. and Andreoni, B. (2011) Impact on Survival of the Number of Lymph Nodes Removed in Patients with Node-Negative Gastric Cancer Submitted to Extended Lymph Node Dissection. European Journal of Surgical Oncology, 37, 305-311. https://doi.org/10.1016/j.ejso.2011.01.013

[22] Wu, C.W., Hsiung, C.A., Lo, S.S., et al. (2006) Nodal Dissection for Patients with Gastric Cancer: A Randomised Controlled Trial. The Lancet Oncology, 7, 309-315. https://doi.org/10.1016/S1470-2045(06)70623-4

[23] Dent, D.M., Madden, M.V. and Price, S.K. (1988) Randomized Comparison of R, and R, Gastrectomy for Gastric Carcinoma. British Journal of Surgery, 75, 110-112. https://doi.org/10.1002/bjs.1800750206

[24] de Steur, W.O., Hartgrink, H.H., Dikken, J.L., Putter, H. and van de Velde, C.J.H. (2015) Quality Control of Lymph Node Dissection in the Dutch Gastric Cancer Trial. British Journal of Surgery, 102, 1388-1393.

[25] Honda, M., Hiki, N., Kinoshita, T., Yabusaki, H., Nunobe, S., Terada, M., Matsuki, A., Sunagawa, H., Aizawa, M., Healy, M.A., Iwasaki, M. and Furukawa, T.A. (2016) Long-Term Outcome of Laparoscopic versus Open Surgery for Clinical Stage I Gastric Cancer: The LOC-1 Study. Annals of Surgery, 264, 214-222. https://doi.org/10.1097/SLA.0000000000001654

[26] Oh, S.Y., Kwon, S., Lee, K.G., Suh, Y.S., Choe, H.N., Kong, S.H., Lee, H.J., Kim, W.H. and Yang, H.K. (2014) Outcomes of Minimally Invasive Surgery for Early Gastric Cancer Are Comparable with Those for Open Surgery: Analysis of 1,013 Minimally Invasive Surgeries at a Single Institution. Surgical Endoscopy, 28, 789-795. 